\title{
Palliative Care and COPD
}

\author{
Tommie Farrell MD
}

\section{CASE}

A 72-year-old male smoker with CAD and COPD was admitted to the ICU with an exacerbation of his COPD severe enough to require intubation. This was his second hospitalization in three months. On the fourth day he showed signs of improvement and tolerated CPAP more than the prior day. Despite this improvement his wife thought he would not want to be kept on the ventilator for this length of time. At her request, the nursing staff asked the resident if a palliative care consult could be made. The palliative care team met with the wife and discussed her concerns about her husband's being on the ventilator. She stated, "After the last time we were here he told me, 'Don't let them keep me on that machine again." The palliative care team asked about other family members who would want to discuss this decision, and she indicated a son. At a meeting later that day the senior resident from the team explained the treatment plans and why they were hopeful that within another day or two extubation would be successful. With the son's encouragement, the patient's wife agreed with the medical team's treatment plan.

The next day the patient was successfully extubated and on the subsequent day was transferred to the floor team. Prior to discharge, the palliative care team visited with the patient who stated that he would prefer to not come to the hospital if possible and preferred not to be intubated again, but that he did not know what to do when he gets this short of breath. They explained the potential services of hospice when a goal of home-based care was desired. The patient was discharged home with a hospice consult and follow-up management was provided by a local hospice team.

Corresponding author: Tommie Farrell, MD Contact Information: Tommie.Farrell@ttuhsc.edu DOI: 10.12746/swrccc2013.0102.015

\section{Discussion}

This is an excellent example of an appropriate palliative care consultation. Among other services, palliative care can accommodate conversations about Goals of Care. Palliative care consults will typically

a) identify key stake holders.

b) identify primary decision maker/s based on written power of attorney or, in its absence, the legal requirements of the state.

c) focus on what the patient would want if $s /$ he could speak (if known).

d) ensure that the patient/family/decision maker has a clear clinical picture of the circumstances and what the likely outcome of the decisions will be (which requires the input and participation of the primary team).

e) help the family know which options are available to the patient/family/decision maker and help them feel empowered in making a decision.

Even in a case in which the short-term prognosis is good, the palliative care team can help achieve these goals, and an appropriate decision was made in this case to continue the current therapeutic course. The palliative care team in this case established a relationship with the patient and his family and was able to ascertain that his goals were more aligned with a hospice approach in the future than with a return to the hospital.

COPD is the third leading cause of death in the U.S. ${ }^{1}$ Prognosis is difficult to determine in this disease process and palliative care and hospice services are underutilized in this population for a variety of reasons. ${ }^{2,3}$ Medicare guidelines for eligibility to enter hospice services for COPD are

a) dyspnea at rest.

b) hypoxia on room air.

c) signs of progression of disease including hospitalization. ${ }^{4}$ 
Hence, virtually all patients admitted to the ICU for COPD would qualify for hospice services if they chose to elect that benefit. Studies show that patients who have consulted palliative care services have a greater satisfaction with their hospital care, lowered rates of admission to the ICU, and decreased health care costs after discharge from the hospital. ${ }^{5,6}$ Of note, patients with palliative care consultation had a reduction of costs with those discharged alive having an adjusted net saving of $\$ 1696$ in direct costs per admission ( $\$ 279$ in direct cost / day) and those dying in the hospital an adjusted net savings of $\$ 4908$ (\$374 in direct cost /day). ${ }^{7}$ Cost reductions were most significant in pharmacy, laboratory, and intensive care unit costs compared with usual care patients.

\section{KEY POINTS}

1. Consider early consultation for palliative care for patients with readmission for COPD even if the short-term prognosis looks favorable.

2. Palliative care services can reduce health care costs.

Author Affiliation: Dr Farrell is in the Department of Family and Community Medicine at TTUHSC and is Director of Palliative Care Services at University Medical Center in Lubbock, TX.

Received: $12 / 10 / 2012$

Accepted: $1 / 2 / 2013$

Reviewers: Kenneth Nugent, MD, Rishi Raj, MD

Published electronically: 4/15/2013

Conflict of Interest Disclosures: None
3. Curtis JR. palliative and end-of-life care for patients with severe COPD. Eur Respir J 2008; 32:796-803.

4. Local Coverage Determination (LCD) for Hospice Cardiopulmonary Conditions (L31540). Federal Register, V. 70, No. 224, dated Tuesday, November 22, 2005 , p. 70537.

5. Gade G, Venohr I, Conner D, et al. Impact of an inpatient palliative care team: a randomized controlled trial. J of Palli Med. 2008; 11(2):180-190.

6. Fromme EK, Bascom PB, Smith SW, et al. Survival, mortality, and location of death for patients seen by a hospital-based palliative care team. J of Palli Med. 2006; 9(4):903-911.

7. Morrison RS, Penrod JD, Cassel JB, et al. Cost savings associated with US hospital palliative care consultation programs. Arch Intern Med. 2008; 168(16): 1783-1790.

\section{REFERENCES}

1. National Center for Health Statistics (2010 preliminary data); available at www.cdc.gov.

2. Pauwels Ra, Bruist AS, Calverley CR, et al. Global strategy for the diagnosis, management, and prevention of chronic obstructive pulmonary disease, NHLBI / WHO workshop summary. Am J Respir Crit Care Med 2001; 163:1256-1276. 